Article

\title{
Evolution of Human Salivary Stress Markers during an Eight-Hour Exposure to a Mediterranean Holm Oak Forest. A Pilot Study
}

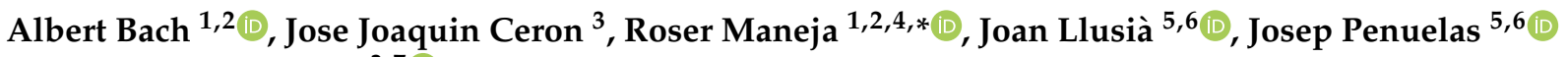 \\ and Damián Escribano ${ }^{3,7}$ (D) \\ 1 Forest Science and Technology Center of Catalonia, Ctra. de St. Llorenç de Morunys, km 2, \\ 25280 Solsona, Spain; albert.bach@ctfc.cat \\ 2 Environment and Human Health Laboratory (EH2 Lab), Ctra. de St. Llorenç de Morunys, km 2, \\ 25280 Solsona, Spain \\ 3 Interdisciplinary Laboratory of Clinical Analysis Interlab-UMU, Regional Campus of International Excellence \\ 'Campus Mare Nostrum', University of Murcia, Campus de Espinardo s/n, Espinardo, 30100 Murcia, Spain; \\ jjceron@um.es (J.J.C.); det20165@um.es (D.E.) \\ 4 Geography Department, B Building, UAB Campus, Autonomous University of Barcelona (UAB), \\ Bellaterra (Cerdanyola del Vallès), 08193 Barcelona, Spain \\ 5 CREAF, Cerdanyola del Vallès, 08193 Barcelona, Spain; j.llusia@creaf.uab.cat (J.L.); \\ Josep.Penuelas@uab.cat (J.P.) \\ 6 CSIC, Global Ecology Unit CREAF-CSIC-UAB, Bellaterra, 08193 Barcelona, Spain \\ 7 Department of Animal and Food Science, School of Veterinary Science, Universitat Autònoma de Barcelona, \\ Cerdanyola del Vallès, 08193 Barcelona, Spain \\ check for \\ updates \\ * Correspondence: roser.maneja@ctfc.cat
}

Citation: Bach, A.; Ceron, J.J.; Maneja, R.; Llusià, J.; Penuelas, J.; Escribano, D. Evolution of Human Salivary Stress Markers during an Eight-Hour Exposure to a Mediterranean Holm Oak Forest. A Pilot Study. Forests 2021, 12, 1600. https://doi.org/10.3390/f12111600

Academic Editors: Rebecca Jordan and Amanda Sorensen

Received: 1 October 2021

Accepted: 13 November 2021

Published: 19 November 2021

Publisher's Note: MDPI stays neutral with regard to jurisdictional claims in published maps and institutional affiliations.

Copyright: (c) 2021 by the authors. Licensee MDPI, Basel, Switzerland. This article is an open access article distributed under the terms and conditions of the Creative Commons Attribution (CC BY) license (https:/ / creativecommons.org/licenses/by/ $4.0 /)$.

\begin{abstract}
The current study analyses the evolution of different human stress markers during an $8 \mathrm{~h}$ exposure to a Mediterranean Holm oak forest. We conducted a pre-post study with thirty-one subjects in which saliva samples were collected before the exposure (baseline) and after 1, 2, 4 and $8 \mathrm{~h}$. Our results show: (A) a significant decrease in cortisol saliva concentrations from the second hour until the end compared to basal time; (B) a significant increase in alpha amylase activity after the first hour of exposure compared to basal time that remained elevated during the rest of the study; (C) a significant decrease in IgA from the fourth hour of exposure compared to the basal time. These findings indicate an effect of forest exposure in salivary biomarkers of stress and provide relevant data for the scientific and healthcare community encouraging further research in the field.
\end{abstract}

Keywords: forest exposure; shinrin-yoku; cortisol; stress markers; forest environments; IgA; health effects

\section{Introduction}

Chronic and acute stress, low capacity to recover from it, and states derived from suffering it, have been linked to different long-term pathologies and psychological disorders [1-5]. The potential of forests as a source of health has led to numerous studies that provide evidence of its benefits [6-8] and strongly correlate exposure to these ecosystems with stress regulation $[9,10]$. Although several studies have proved that exposure to forests lowers stress markers compared to urban settings [7,11-16], other studies found no significant differences [17-20].

From the existing literature, a recent review and meta-analysis from Antonelli et al. (2019) concludes that exposure to forests significantly affects cortisol levels. Most of the studies included in the review considered short-term exposures to forested ecosystems (from $15 \mathrm{~min}$ to $4 \mathrm{~h}$ ). To date, limited data are available to understand the effects of forests on stress hormones [21] and no studies have assessed the effect of long-term exposures to forest environments. 
Saliva sampling is widely used as a non-invasive sample in stress studies having various advantages such as the possibility of conducting repeated sampling over short time intervals facilitating ongoing monitoring. Salivary cortisol is the most used stress marker within the studies analysing forest effects on stress regulation [21]. The levels of salivary cortisol can be useful to study psycho-physical benefits of a specific intervention on the so-called stress system because they are indicative of the hypothalamic pituitaryadrenal (HPA) axis activity and the integrated effect of an anti-stress practice upon a person's neuro-endocrinological system, [22,23]. Salivary alpha-amylase (sAA) is secreted by the salivary glands (mainly in the parotid) in response to adrenergic activity. Previous studies suggest sAA as a surrogate marker of the autonomic nervous system (ANS) [24,25] and have shown that sAA levels rise in response to both physical and psychological stress [26-28]. It has also been used to evaluate the possible positive effect of natural environment in humans $[17,29]$. Salivary immunoglobulin A $(\operatorname{IgA})$ can be increased by both parasympathetic and sympathetic nerve systems [30,31]. The IgA expression has been related to mental stress in humans [32]. Furthermore, saliva has also been used as a marker to evaluate oxidative stress in humans [33]. Although one study analysed oxidative stress through malondialdehyde MDA [15], to the authors' knowledge, the total antioxidant capacity (TAC) has not been used in forests and human health studies, and may constitute a relevant biomarker of oxidative stress.

The aim of this study was to analyse the variation and evolution of a combination of human salivary stress biomarkers (cortisol, alpha amylase, IgA and TAC) which reflect different systems involved in stress mechanism, during an $8 \mathrm{~h}$ exposure to a Mediterranean forest ecosystem.

\section{Materials and Methods}

\subsection{Participants}

A total of thirty-one subjects ( 21 females and 10 males) were recruited from the Autonomous University of Barcelona and the Gym Chain "Duet Fit". Inclusion criteria were: (A) aged between 20 and 40 years old; (B) index of body mass between 19 and 25; (C) non-smokers (at least 6 months before the study); (D) no respiratory pathology (asthma, chronic bronchitis or respiratory allergies); and (E) no pathologies affecting the immune system during the study. Participants included in the study were urban dwellers living in Barcelona city that had no regular contact with the studied forest area. In the registration form participants were asked for the periodicity of forest visits and all of them replied that they visited a forest area once per month or less.

Two days before the study, participants were asked not to consume alcohol to control for its effects. After providing the study description and fully informing participants about the study objectives and design, written informed consent was received from each participant in advance. This study was approved by the Ethics Committee of Granollers Hospital, Spain, on the 26 June 2018 (CEIC Code 20182020).

\subsection{Study Site}

The study site was located in Montseny Natural Park-Biosphere Reserve (NE Iberian Peninsula) (Figure 1) in a Holm oak forest dominated by Quercus ilex (2400 trees per hectare). The average Diameter at Breast Height (DBH) for Q. ilex was $16.41 \pm 1.037 \mathrm{~cm}$. Other species such as Castanea sativa, Juniperus communis or Erica arborea were identified in the study area but not abundantly. Concerning forest structure, vegetation cover at $8 \mathrm{~m}$ height was $100 \%$ whereas the layers below did not exceed coverages of $10 \%$. This forest area has an altitude range from 860 to $972 \mathrm{~m}$. During the study, records taken under the canopy level registered an average temperature of $23.87 \pm 0.18^{\circ} \mathrm{C}$ and an average relative humidity of $53.70 \pm 0.50 \%$ during the sampling period. 

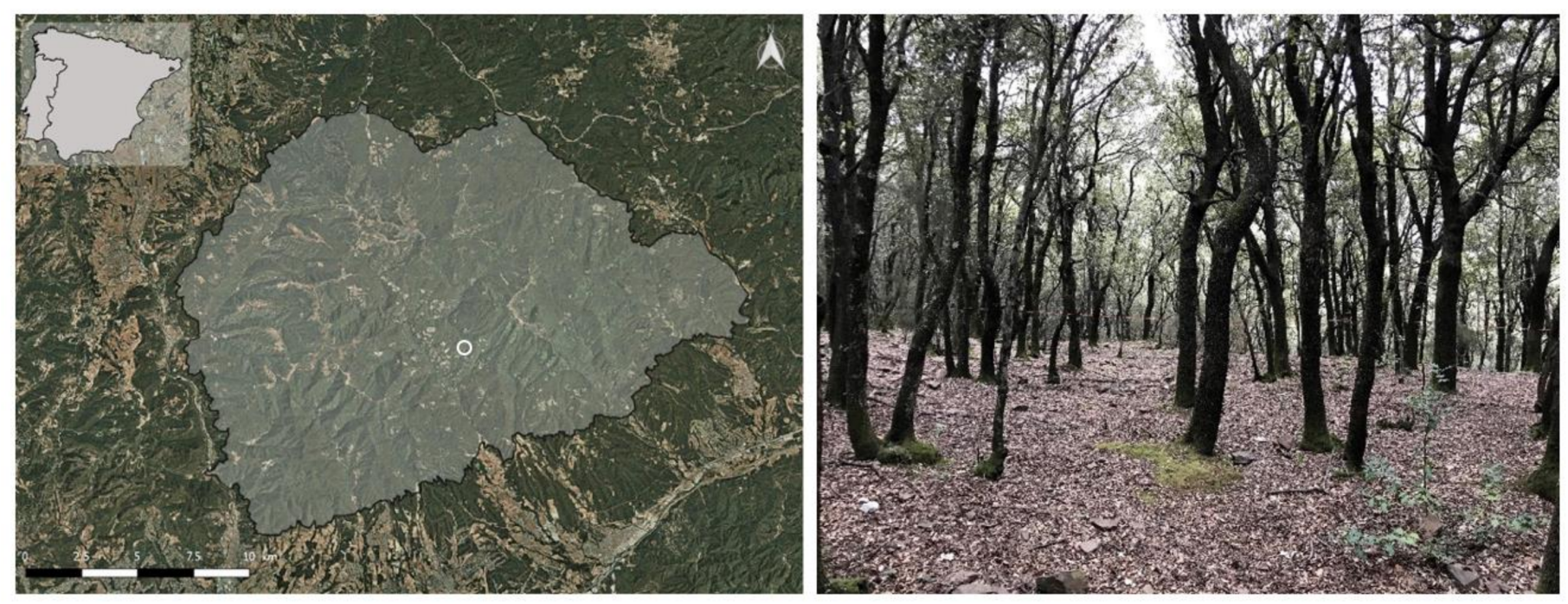

Figure 1. Site location and experimental scenario.

\subsection{Study Design}

We used a pretest-posttest experimental approach to assess the effects of forest exposure on stress markers considering the pretest measurement (before forest exposure) as the "baseline". The study was carried out the 20 July 2018 and started at 9:30 in the Hospital of Sant Celoni (NE Catalonia, Spain), where the first saliva samples were collected avoiding any previous contact with the forested area. The sample collection was carried out in a separate room of the hospital (with no people from the hospital or visiting the hospital) big enough for all the participants. The room had white walls and some windows facing the street in front of the hospital. During sample collection, there was no music, and no perfumed products or air freshener were applied $48 \mathrm{~h}$ before the study. Participants were asked to sit in chairs for $15 \mathrm{~min}$ before collecting the samples. After data collection in the hospital, participants were taken to the forest where a light breakfast was provided. At 11:00 participants began the forest exposure until 19:00 having lunch in the forest at 14:00. They were asked to walk through the forest, and to rest and sit if they were tired. Intense physical activity such as running or conducting any sport was forbidden. Participants were asked to indicate if they conducted yoga, meditation or any other pro-active activity (as described in [34]). Once the experimental study started, saliva samples were collected after $1,2,4$ and $8 \mathrm{~h}$ of forest exposure, leading to a total of 5 samples per participant including the baseline sample (Figure 2). Based on a previous review [21] we identified that most of the studies analysed exposures of $1 \mathrm{~h}$ or less, and we selected the aforementioned exposure times to assess the long forest exposure effects on human stress biomarkers.

\section{City Forest Exposure}

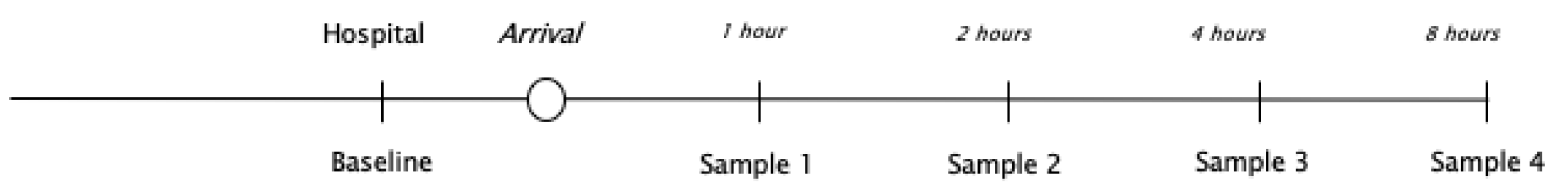

Figure 2. Sampling design diagram.

Although aware of the limitation of not conducting a randomized controlled trial, we prioritized a bigger sample size exposed to the forest (31 individuals instead of 15) and the analysis of the evolution of the forest exposure itself not compared to an urban 
setting. Considering that several studies have found lower cortisol concentrations after forest exposure compared to urban environments' exposure [7,11-14,19,35,36], we focused on identifying the variation in salivary stress markers in the forest during an $8 \mathrm{~h}$ exposure rather than again comparing these environments with the urban ones. Considering the current literature, we also aimed at analysing whether these previously reported differences between forested and urban settings were due to a decrease in stress markers in the forest or simply to an increase in urban environments' testing of the forest environment itself. Furthermore, it is well-known that the stress markers analysed in our study follow a circadian rhythm $[14,37]$. However, Yamaguchi et al. (2006) showed that sAA activity circadian rhythm fluctuations were much smaller than the stressor-induced variations, and that the forest constitutes a good environment in which people experienced significantly less environment-derived stress, which enabled observations of exercise-induced physiological effects to be made [29]. In addition, other studies have shown how certain stress biomarkers present a stabilization after the morning peak (approximately $30 \mathrm{~min}$ after waking up $[38,39]$. Thus, sampling times chosen in this study do not include the morning peak period of these stress biomarkers as participants were picked up from Barcelona city and shifted to the hospital $1 \mathrm{~h}$ and $20 \mathrm{~min}$ before the first sampling time (baseline). For all the aforementioned reason, we designed the work presented here as a pilot study to assess the effects of long exposure to urban ecosystems and to encourage future research in this field of research.

\subsection{Saliva Sampling Procedure}

Saliva was collected for $1 \mathrm{~min}$ by passive flow under supervision, using $5 \mathrm{~mL}$ standard microcentrifuge polystyrene tubes with round bottoms $(12 \mathrm{~mm} \times 75 \mathrm{~mm})$. To minimize any potential physiological effects about responses to salivary biomarkers, before the beginning of the saliva collection participants were not allowed to eat, or have coffee or caffeinated soft drinks [26]. Furthermore, participants were asked to rest in the same spot where saliva was collected for 15 min without conducting any activity before sample collection. Each sample was refrigerated or stored on ice until arrival at the laboratory. Afterwards, samples were weighed and then centrifuged at $3000 \times g$ for $10 \mathrm{~min}$ at $4{ }^{\circ} \mathrm{C}$ to remove cells. The supernatant was transferred to $1.5 \mathrm{~mL}$ Eppendorf tubes and stored at $-80^{\circ} \mathrm{C}$ until analysis $[27,40]$.

\subsection{Laboratory Salivary Methods}

Figure 3 shows the procedure flow of an individual analysis. Below, the particular analysis of each stress biomarker is detailed.

Cortisol was evaluated by a solid-phase, competitive chemiluminescent enzyme immunoassay (Immulite; Siemens, Erlangen, Germany), displaying within-run and betweenrun imprecision lower than $10 \%$, recovery rates between $92 \%$ and $120 \%$, and a limit of detection of $0.2 \mathrm{nmol} / \mathrm{L}$ [41].

sAA activity was measured using a colorimetric commercial kit (Alpha-Amylase, Beckman Coulter Inc., Fullerton, CA, USA) following the International Medicine (IFCC) method [42,43], as previously reported and validated [41].

IgA was evaluated with a commercial ELISA kit (Bethyl, Montgomery, TX, USA), with a within-run and between-run imprecision lower than $10 \%$, recovery rates between $91 \%$ and $112 \%$, and a limit of detection of $0.05 \mathrm{mg} / \mathrm{L}$ [44].

Two assays commonly used to evaluate the total antioxidant capacity (TAC) were used. Cupric reducing antioxidant capacity (CUPRAC) is based on the generation of a complex containing $\mathrm{Cu}^{2+}$ and one chelating agent, in this case bathocuproinedisulfonic acid disodium salt, and its reduction to $\mathrm{Cu}^{1+}$ by the non-enzymatic antioxidants present in a sample [45]. Results were compared with a standard curve obtained using Trolox and were also expressed in millimoles of Trolox equivalents per litre. The ferric reducing ability of plasma (FRAS) measurement is based on the assay described by Benzie and Strain [46]. A reaction mixture containing ferric-tripyridyltriazine $\left(\mathrm{Fe}^{3+}\right)$ is reduced to the 
ferrous $\left(\mathrm{Fe}^{2+}\right)$ form by the non-enzymatic antioxidants provided by the sample. Ferric chloride hexahydrate $\left(\mathrm{FeCl}_{3} \cdot 6 \mathrm{H}_{2}\right)$ solution was used to produce a standard curve and was compared with the sample results that were expressed in millimoles of $\mathrm{Fe}^{2+}$ equivalents per litre.

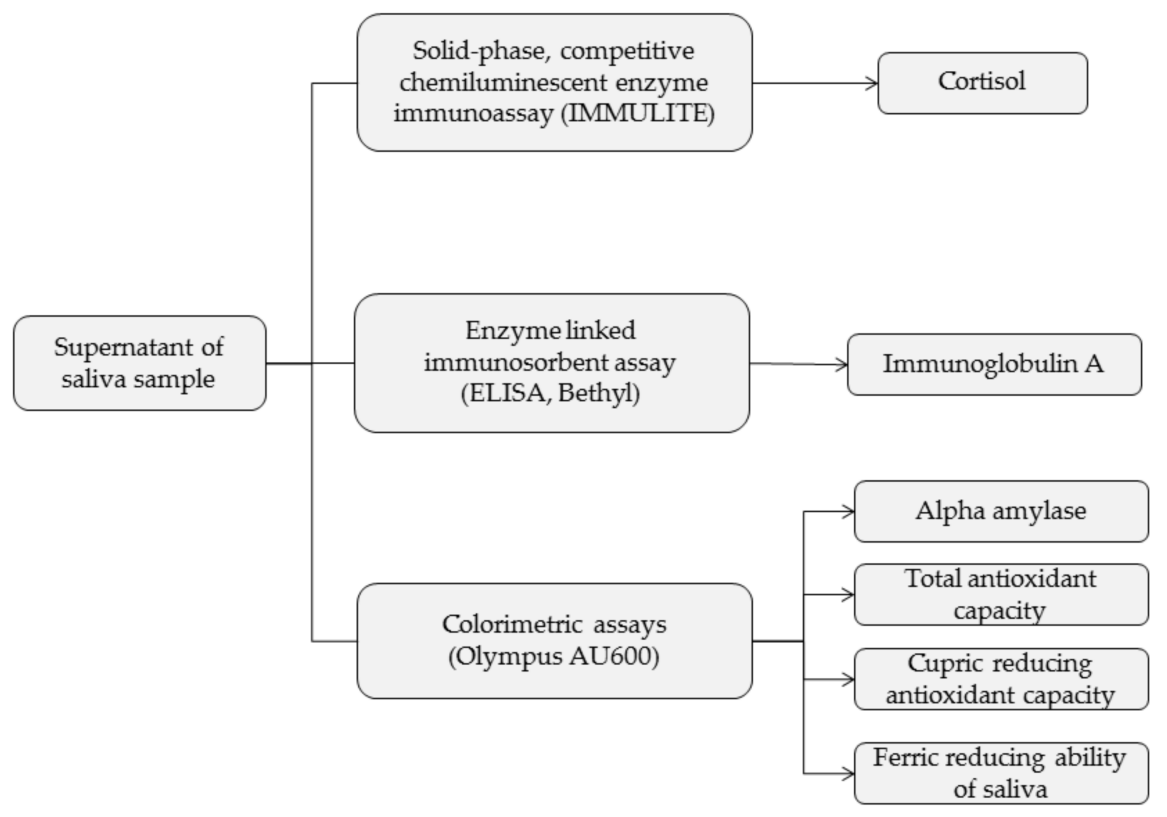

Figure 3. Flow of procedures of an individual analysis.

\subsection{Data Analysis}

The different salivary biomarkers concentrations were evaluated for normality of distribution, using the Kolmogorov-Smirnov test. As the results did not meet the normal distribution criteria, a non-parametric test of repeated measures one-way ANOVA with a Friedman's test and a Dunn's multiple comparisons post-test were used to compare the different levels of salivary biomarkers between sampling times. To study the possible effect of gender on the salivary levels, a two-way repeated measures ANOVA test and a Bonferroni post hoc test were performed for the 'sampling time-gender' influence. All statistical analyses were performed using a commercial statistics package, GraphPad Prism 6 (GraphPad Software Inc., La Jolla, CA, USA). A $p<0.05$ value was considered significant.

In addition, a stand-alone power programme for statistical testing (G-Power) was employed to compute the achieved power (1- $\beta$ error probability) in each analysis, with a significance level of $\alpha=5 \%$ and a power of $80 \%$. Results were as follows: cortisol (statistical power $=88 \%$ ); sAA (statistical power $=99 \%$ ); IgA (statistical power $=99 \%)$, CUPRAC (statistical power $=99 \%$ ); and FRAS (statistical power $=99 \%$ )

\section{Results}

Salivary cortisol samples show a decreasing tendency during the $8 \mathrm{~h}$ exposure to the forest environment (Figure 4). After one-hour exposure $(0.305 \mu \mathrm{g} / \mathrm{dL}$; range $0.24-0.44 \mu \mathrm{g} / \mathrm{dL}$; $25-75$ th percentiles) data show a decrease, although this is not significant in relation to baseline $(0.522 \mu \mathrm{g} / \mathrm{dL}$; range $0.38-0.60 \mu \mathrm{g} / \mathrm{dL} ; 25-75$ th percentiles). For the samples collected after $2(0.232 \mu \mathrm{g} / \mathrm{dL}$; range $0.17-0.32 \mu \mathrm{g} / \mathrm{dL} ; 25-75$ th percentiles $), 4(0.273 \mu \mathrm{g} / \mathrm{dL}$; range $0.21-0.33 \mu \mathrm{g} / \mathrm{dL} ; 25-75 \mathrm{th}$ percentiles $)$ and $8 \mathrm{~h}(0.148 \mu \mathrm{g} / \mathrm{dL}$; range $0.11-0.22 \mu \mathrm{g} / \mathrm{dL}$; 25-75th percentiles) in the forest, there is a significant decrease in salivary cortisol levels in comparison with the baseline measurements $(p<0.0001)$. Comparing sampling times, significant decreases are found between sampling times A) $1 \mathrm{~h}$ and $2 \mathrm{~h}(p<0.05), \mathrm{B}) 1 \mathrm{~h}$ and $8 \mathrm{~h}$ measures $(p<0.05)$, and for $4 \mathrm{~h}$ and $8 \mathrm{~h}(p<0.0001)$. 


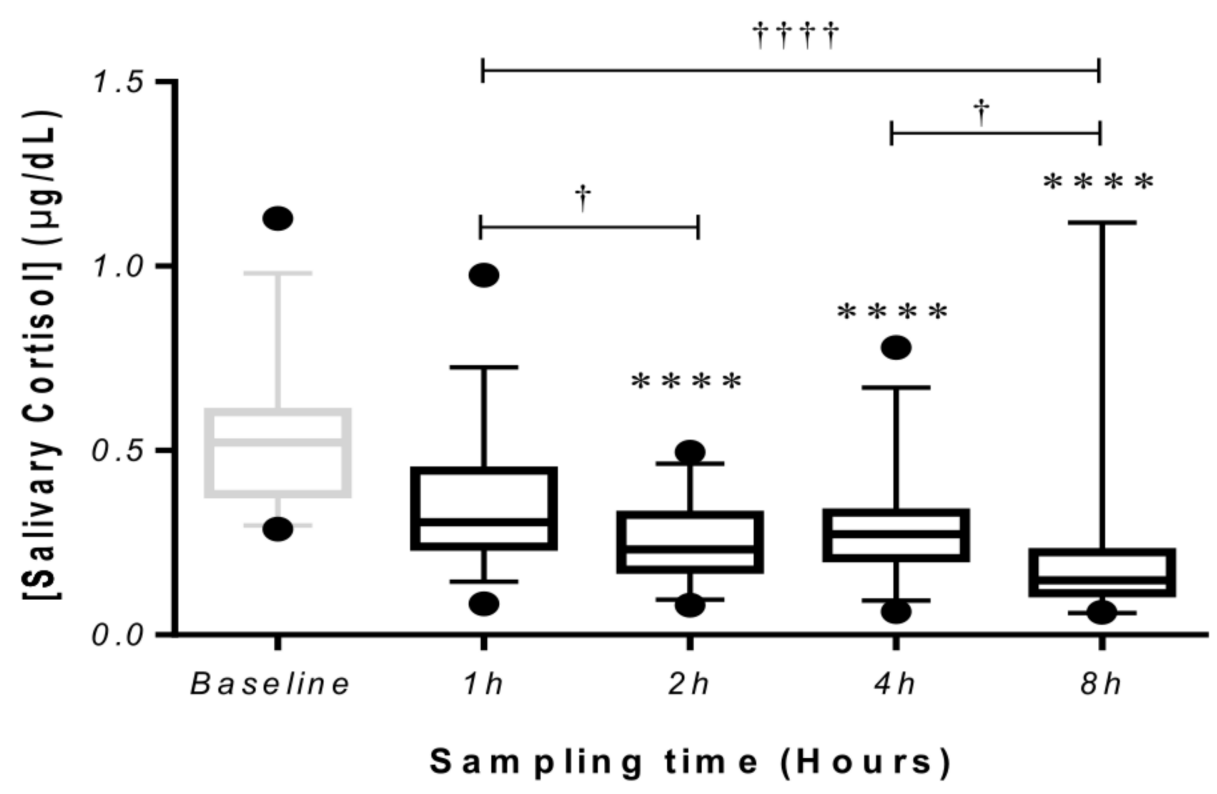

Figure 4. Salivary cortisol changes box plots. The boxes (25-75th percentiles) show the median concentrations of salivary marker (line within the box) and whisker plots represent the minimum (5th percentiles) and maximum values (95th percentiles). ${ }^{* * *} p<0.0001$ compared to baseline values. $+p<0.05$, and $++++p<0.0001$ comparing between different sampling times. $\mathrm{N}=31$.

Alpha amylase samples show a significant increase at $1 \mathrm{~h}(116820 \mathrm{Ul} / \mathrm{L}$; range 57720-187140 Ul/L; 25-75th percentiles) and in the measures obtained after this exposure time compared to the baseline values (Figure 5). Salivary IgA levels (Figure 6) show a significant decrease in $4 \mathrm{~h}(24.41 \mathrm{mg} / \mathrm{dL}$; range $17.48-39.99 \mathrm{mg} / \mathrm{dL} ; 25-75$ th percentiles $)$ and $8 \mathrm{~h}(23.79 \mathrm{mg} / \mathrm{dL}$; range $11.56-37.67 \mathrm{mg} / \mathrm{dL} ; 25-75$ th percentiles $)$ measurements compared to the baseline values ( $p<0.001$ and $p<0.01$ respectively). This decrease is also significant $(p<0.05)$ when comparing both sampling times with sampling time of $2 \mathrm{~h}$ (33.47 $\mathrm{mg} / \mathrm{dL}$; range $16.89-47.89 \mathrm{mg} / \mathrm{dL} ; 25-75$ th percentiles).

The stress oxidative markers analysed did not present significant variations during the forest exposition. Salivary CUPRAC levels were $0.195 \mathrm{mmol} / \mathrm{L}$ (range $0.12-0.27 \mathrm{mmol} / \mathrm{L}$; 25-75th percentiles) at baseline and $0.197 \mathrm{mmol} / \mathrm{L}$ (range $0.12-0.27 \mathrm{mmol} / \mathrm{L} ; 25-75$ th percentiles), $0.178 \mathrm{mmol} / \mathrm{L}$ (range $0.12-0.28 \mathrm{mmol} / \mathrm{L} ; 25-75$ th percentiles), $0.191 \mathrm{mmol} / \mathrm{L}$ (range 0.14-0.28 mmol/L; 25-75th percentiles), and $0.198 \mathrm{mmol} / \mathrm{L}$ (range $0.14-0.28 \mathrm{mmol} / \mathrm{L}$; 25-75th percentiles) at 1, 2, 4 and $8 \mathrm{~h}$ after forest exposition, respectively. Salivary FRAS levels were $0.366 \mathrm{mmol} / \mathrm{L}$ (range $0.17-0.58 \mathrm{mmol} / \mathrm{L} ; 25-75$ th percentiles) at baseline and $0.414 \mathrm{mmol} / \mathrm{L}$ (range 0.16-0.58 mmol/L; 25-75th percentiles), $0.338 \mathrm{mmol} / \mathrm{L}$ (range $0.22-0.56 \mathrm{mmol} / \mathrm{L}$; 25-75th percentiles), $0.375 \mathrm{mmol} / \mathrm{L}$ (range $0.24-0.54 \mathrm{mmol} / \mathrm{L} ; 25-75$ th percentiles) and $0.392 \mathrm{mmol} / \mathrm{L}$ (range $0.23-0.61 \mathrm{mmol} / \mathrm{L} ; 25-75 \mathrm{th}$ percentiles) at 1, 2, 4 and $8 \mathrm{~h}$ after forest exposition, respectively.

The two-way ANOVA analysis revealed no significant effects of gender on any of the evolutions of the analytes studied (Table 1). 


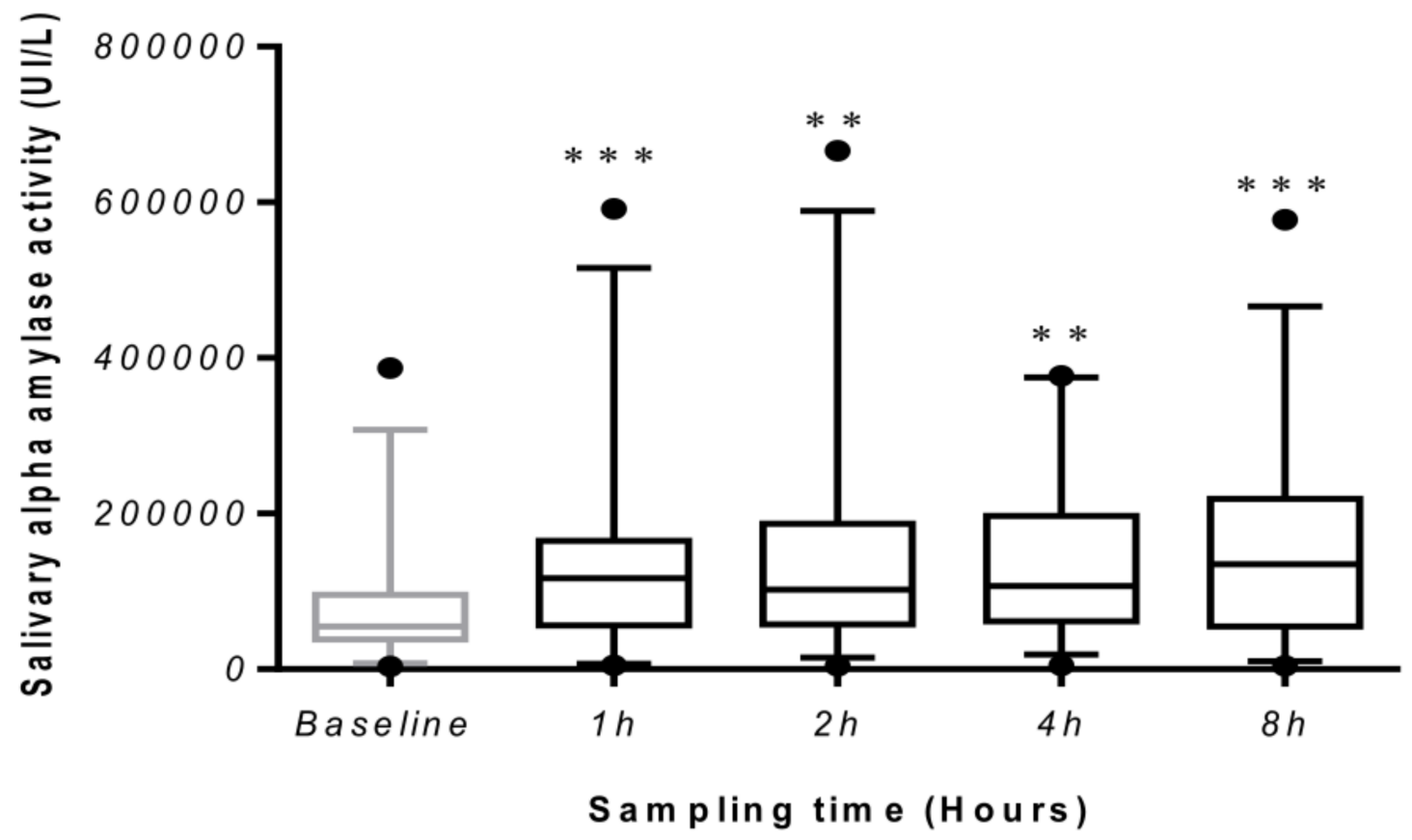

Figure 5. Salivary alpha amylase changes box plots. The boxes (25-75th percentiles) show the median concentrations of salivary marker (line within the box) and whisker plots represent the minimum (5th percentiles) and maximum values (95th percentiles). ${ }^{* *} p<0.01$ and ${ }^{* * *} p<0.001$ compared to baseline values. $\mathrm{N}=31$.

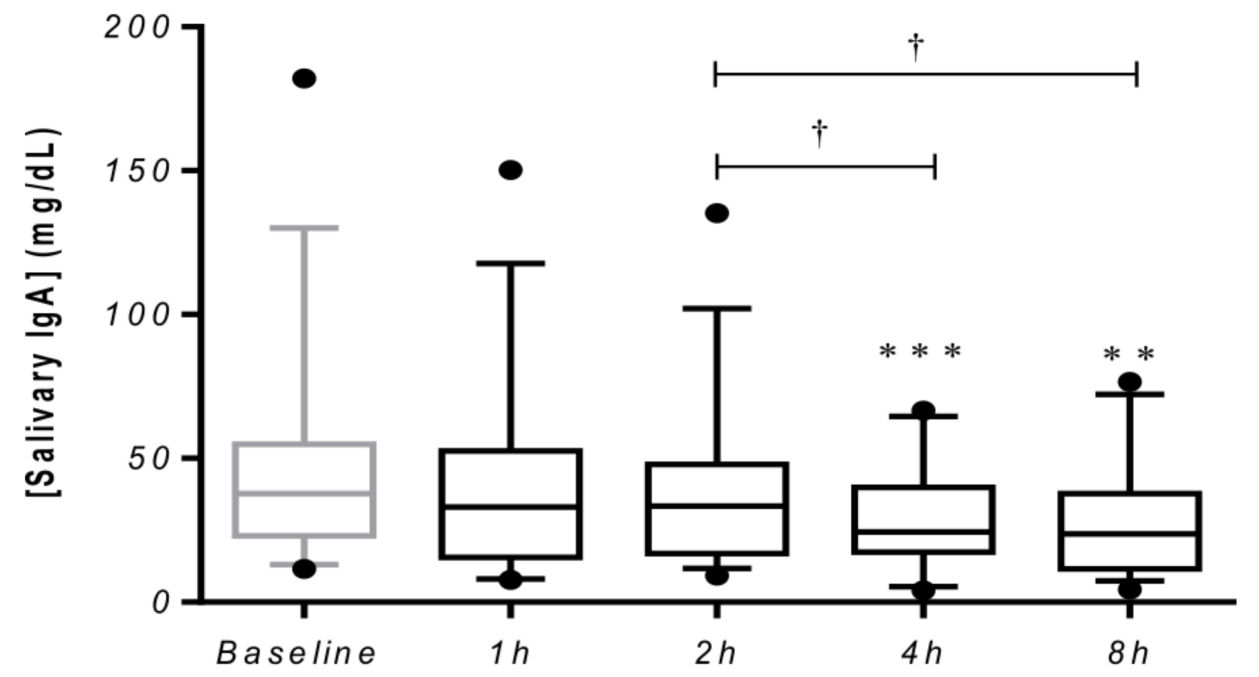

Sampling tim e (Hours)

Figure 6. Salivary IgA changes box plots. The boxes (25-75th percentiles) show the median concentrations of salivary marker (line within the box) and whisker plots represent the minimum (5th percentiles) and maximum values (95th percentiles). ${ }^{* *} p<0.01$ and ${ }^{* * *} p<0.001$ compared to baseline values. $+p<0.05$ comparing between different sampling times. $\mathrm{N}=31$. 
Table 1. Two-way ANOVA analysis results, median and standard deviation per gender and timing.

\begin{tabular}{|c|c|c|c|c|c|c|c|}
\hline & & & Cortisol & sAA & $\operatorname{Ig} A$ & CUPRAC & FRAS \\
\hline & $F$ & & 0.4275 & 0.0867 & 2.135 & 0.6170 & 0.7348 \\
\hline & $p$-value & & 0.5316 & 0.7758 & 0.1821 & 0.4548 & 0.4163 \\
\hline \multirow{10}{*}{$\begin{array}{l}\text { Median } \pm \text { SD } \\
(\mu \mathrm{L} / \mathrm{dL} \text { or } \mathrm{UI} / \mathrm{L})\end{array}$} & \multirow{2}{*}{ Baseline } & Women & $0.53 \pm 0.11$ & $62,940 \pm 70,704$ & $9.36 \pm 22.37$ & $0.19 \pm 0.08$ & $0.29 \pm 0.22$ \\
\hline & & Men & $0.50 \pm 0.11$ & $47,300 \pm 111,139$ & $1.34 \pm 50.50$ & $0.21 \pm 0.16$ & $0.44 \pm 0.28$ \\
\hline & \multirow{2}{*}{$1 \mathrm{~h}$} & Women & $0.27 \pm 0.24$ & $138,820 \pm 112,519$ & $3,26.40 \pm 24.65$ & $0.15 \pm 0.12$ & $0.30 \pm 0.29$ \\
\hline & & Men & $0.34 \pm 0.24$ & $76,790 \pm 171,402$ & $3,39.44 \pm 39.89$ & $0.21 \pm 0.11$ & $0.42 \pm 0.25$ \\
\hline & \multirow{2}{*}{$2 \mathrm{~h}$} & Women & $0.23 \pm 0.12$ & $99,040 \pm 141,090$ & $8.14 \pm 23.23$ & $0.20 \pm 0.10$ & $0.41 \pm 0.24$ \\
\hline & & Men & $0.24 \pm 0.12$ & $103,510 \pm 159,407$ & $34.80 \pm 35.74$ & $0.17 \pm 0.09$ & $0.32 \pm 0.19$ \\
\hline & \multirow{2}{*}{$4 \mathrm{~h}$} & Women & $0.26 \pm 0.10$ & $107,160 \pm 108,249$ & $2,26.34 \pm 17.06$ & $0.19 \pm 0.12$ & $0.39 \pm 0.28$ \\
\hline & & Men & $0.30 \pm 0.10$ & $103,509 \pm 114,329$ & $23.82 \pm 18.88$ & $0.19 \pm 0.08$ & $0.36 \pm 0.20$ \\
\hline & \multirow{2}{*}{$8 \mathrm{~h}$} & Women & $0.15 \pm 0.08$ & $147,880 \pm 98,885$ & $34.09 \pm 18.50$ & $0.20 \pm 0.19$ & $0.42 \pm 0.37$ \\
\hline & & Men & $0.21 \pm 0.08$ & $79,830 \pm 169,277$ & $13.89 \pm 22.43$ & $0.18 \pm 0.06$ & $0.31 \pm 0.16$ \\
\hline
\end{tabular}

\section{Discussion}

The present study analysed the evolution of a combination of different human salivary stress markers during an $8 \mathrm{~h}$ exposure to a forest ecosystem. We found different trends depending on the stress marker; although cortisol and IgA showed a significant decrease during the forest exposure, alpha amylase increased significantly after it. In addition, the studied biomarkers showed different dynamics with sAA varying earlier, whereas cortisol and $\operatorname{IgA}$ changed at later stages.

We observed a decreasing trend in cortisol levels during forest exposure, which was significant after the first $2 \mathrm{~h}$. A significant cortisol decrease in serum after contact with forests has been previously reported [47]. Our results are also in line with other studies that showed lower salivary cortisol levels in the forest compared to urban settings $[7,11-14,19,35]$. The cortisol delayed response found in our study may be due to the fact that cortisol changes represent the HPA system, which usually responds later to stress than other pathways also involved in the stress response, such as the adrenergic systems. In addition, the delayed hormone response may be modelled by different factors: the trip from the hospital to the forest area, the acclimation and adaptation process of the volunteers, and the physical exercise that have been previously observed to induce cortisol levels increase [48]. Although previous studies have observed significant changes in cortisol levels in short-time exposures [21], our results showing this delayed decrease may explain why some other authors found no significant changes just after short forest exposures [20]. Furthermore, the significant differences we found between sampling times show that the decreasing effect of forest exposure lasted for the $8 \mathrm{~h}$ exposure. Nevertheless, the non-significant changes observed between sampling times of 2 and $4 \mathrm{~h}$ may involve lunchtime when participants were asked to join at a meeting point and shortly modified their experience in the forest. In this sense, stress-related feelings caused by hunger may have already played a role in the decrease in cortisol levels in the break between those sample times, although a significant increase in cortisol levels was not reported. This is important to note because cortisol concentrations can rebound after a stimuli [49]. Thus, our results follow the findings of this field of study, in which no concentration rebounds have been reported to date. Overall, the decrease in cortisol indicates a decrease in the stress levels and therefore a benefit of the forest exposure.

We identified a significant increase in sAA concentrations during the first hour of exposure but no significant variations thereafter. The increase in sAA found in our study may be due to the fact that participants conducted a low intensity physical activity, which 
is known to increase sAA activity [50]. In a previous study assessing urban nature experiences, sAA decreases were observed only for the participants that conducted low physical activities, even after adjusting the sAA levels for its diurnal rise, whereas activity type did not influence the cortisol response [51]. Therefore, physical exercise conducted by participants in our study appears to be a reasonable explanation in regard to the initial increase and stabilization of sAA during the $8 \mathrm{~h}$ forest exposure. Concerning the stability and non-significant variation of this hormone after the first hour, a previous study in which participants viewed a forest also obtained non-significant variations in salivary amylase [52]. However, other forms of stress reduction interventions, such as yoga, have been reported to decrease sAA levels compared to baseline values [53], and one previous study found that salivary amylase was reduced in the forest in comparison to an urban setting after a 20 min walk [29]. Although forests may constitute a habitat with fewer environment-derived stressors, other factors may play a role in salivary alpha amylase activity and further studies are needed to clarify these observed trends.

IgA concentrations showed a decreasing trend, but this was only significant from the sampling time of $4 \mathrm{~h}$ when compared to baseline values. These delayed changes may be in line with those observed by Tsunetsugu et al., [2], who found no changes in IgA concentrations when walking on or viewing a forest for $15 \mathrm{~min}$. The salivary IgA response to stress is complex [54] and the non-significant tendency we found for shorter exposure times is unclear. A plausible explanation to the decrease in IgA found in our study could be due to a potential relaxing effect of forest exposure. Decreases in IgA after forest exposure have been previously described [54] and further studies should be performed to elucidate the cause and possible implications of this decrease. The different responses between cortisol and IgA could be due to the different systems involved in their regulation - sympathetic activity for IgA or the HPA system in case of cortisol [32]. In addition, the salivary IgA half-life is much longer, which may be an influence in the assessment of stress in real-time studies [55]. This fact could explain the delay in salivary IgA response observed in our study and the fact that the initial high levels were maintained during for a longer time.

Overall, our results indicate that forests can produce changes in salivary human stress marker patterns, as seen in decreases in cortisol and IgA, and increases in sAA. However, future research is needed to provide a better assessment of the confounding factors (such as physical activity or circadian rhythm implications, or the influence of travelling and acclimation), and to improve our understanding of stress marker variation in longer exposures to forests.

Our findings, framed in a Mediterranean Holm oak forest, are among the few obtained to date in this forest type because most of the studies have been conducted in Asian countries $[34,56]$ where biotic and abiotic conditions may differ. A previous systematic review could not identify trends in cortisol levels for this particular forest type among the literature [34]. Nevertheless, interest in Mediterranean Holm oak forests is increasing among the scientific community and new research is now being conducted on forest elements connected to human health within these biomes. A recent study undertaken in the same forest type and site reported significant concentrations of monoterpenes (Biogenic Volatile Organic Compounds) [57], a group of chemical compounds that have been previously shown to have stress relief effects [58]. Therefore, our pilot study, which showed a significant decreasing trend in some of the salivary stress biomarkers, constitutes a further step in understanding the potential benefits of exposure to Mediterranean Holm oak forests.

\section{Limitations}

We are aware of the different limitations of this experimental design. First, we did not include a control group in the study. This implies that we cannot control the potential effects of confounding factors associated with the forest, or isolate the regular variations of the circadian rhythm. Furthermore, the lack of a control group did not allow us to rule out 
the possibility that the effects found in our participants may be due to the elimination of their stressful routine. Nevertheless, we prioritized a bigger sample size exposed to the forest and a more accurate analysis of the evolution of the forest exposure itself, as stated in the study design (Materials and Methods) section of this manuscript.

In addition, the lack of a control group did not allow us to control for the well-known circadian changes in the analysed stress markers [3,4]. In our results, we were able to clearly identify delayed responses and sampling times with no significant changes compared to the baseline or previous sampling times. This may show that the interaction with other confounding factors, and the potential effect of the forest ecosystems, may be greater than that of the circadian rhythm, as reported by previous studies [29]. Furthermore, in our study no significant changes in TAC, measured via CUPRAC and FRAS capacity, were observed and the levels remained constant throughout the study. In the study of Borisenkov et al. (2007), where the diurnal changes in the TAC activity in human saliva were studied, a peak at 6:00 was found. However, the levels after 9:00 also remained constant [38]. Our sampling was performed after the peak upon awakening.

Another limitation is that pace and walking distance were not registered during the study. Given the variability we observed, especially at the beginning of the exposure, and the influence of physical exercise on stress marker concentrations in saliva, we strongly encourage future research to include these parameters in their measurements. Despite the methodological limitations mentioned above, we are convinced that the design of the study provides relevant findings regarding long-exposure variations in human salivary stress markers in this Mediterranean forest ecosystem.

\section{Conclusions}

This experimental pre-post study reported: (A) a decrease in cortisol saliva concentrations during an $8 \mathrm{~h}$ exposure to forest, which significant from the second hour until the end; (B) a significant increase in sAA activity during the first hour of exposure and its stabilisation during the remainder of the study; and (C) a significant decrease in IgA from the fourth hour of exposure. These findings would support the physiological (cortisol) and psychological (IgA) relaxing effects of forest exposure. Overall, our results suggest that time spent in the forest may be an important factor when considering stress biomarkers response to these environments. Therefore, further research in this field and potential applications in the healthcare sector should consider the delayed response of some stress biomarkers. In addition, this is the first study reporting the decrease in stress biomarkers in a Mediterranean Holm oak forest.

Author Contributions: Conceptualization, A.B., R.M., J.J.C., J.P., J.L. and D.E.; methodology, A.B., J.J.C., J.P., J.L. and D.E.; validation, R.M., J.J.C. and J.P.; formal analysis, A.B., J.J.C. and D.E.; investigation, A.B., R.M., J.J.C., J.P., J.L. and D.E.; resources, R.M., J.J.C. and J.P.; writing-original draft preparation, A.B., R.M., J.J.C., J.P., J.L.; writing-review and editing, A.B., R.M., J.J.C., J.P., J.L. All authors have read and agreed to the published version of the manuscript.

Funding: The research leading to these results has received funding from "la Caixa" Foundation.

Acknowledgments: Our special gratitude goes to those volunteers who participated in this study. We particularly acknowledge Teresa Romanillos for her support when preparing and conducting the experimental study. We would also like to thank the Sant Celoni Hospital for their logistic support and attention provided.

Conflicts of Interest: The authors declare no conflict of interest.

\section{References}

1. Jordan, J.; Gurr, E.; Tinline, G.; Giga, S.; Faragher, B.; Cooper, C. HSE Health \& Safety Executive Beacons of Excellence in Stress Prevention. 2003; ISBN 0717627098. Available online: https://www.hse.gov.uk/research/rrpdf/rr133.pdf (accessed on 5 November 2021).

2. Goodwin, R.D.; Davidson, K.W.; Keyes, K. Mental disorders and cardiovascular disease among adults in the United States. J. Psychiatr. Res. 2009, 43, 239-246. [CrossRef] [PubMed] 
3. Todaro, J.F.; Shen, B.J.; Raffa, S.D.; Tilkemeier, P.L.; Niaura, R. Prevalence of anxiety disorders in men and women with established coronary heart disease. J. Cardiopulm. Rehabil. Prev. 2007, 27, 86-91. [CrossRef] [PubMed]

4. Player, M.S.; Peterson, E.L. Anxiety disorders, hypertension, and cardiovascular risk: A review. Int. J. Psychiatry Med. 2011, 41, 365-377. [CrossRef] [PubMed]

5. Aldwin, C.M. Stress, Coping and Development: An Intergrative Perspective; The Guilford Press: New York, NY, USA, 2007; ISBN 9781572308404.

6. Tsunetsugu, Y.; Park, B.J.; Miyazaki, Y. Trends in research related to "shinrin-yoku" (taking in the forest atmosphere or forest bathing) in Japan. Environ. Health Prev. Med. 2010, 15, 27-37. [CrossRef]

7. Park, B.J.; Tsunetsugu, Y.; Kasetani, T.; Kagawa, T.; Miyazaki, Y. The physiological effects of Shinrin-yoku (taking in the forest atmosphere or forest bathing): Evidence from field experiments in 24 forests across Japan. Environ. Health Prev. Med. 2010, 15, 18-26. [CrossRef]

8. Song, C.; Ikei, H.; Miyazaki, Y. Physiological effects of nature therapy: A review of the research in Japan. Int. J. Environ. Res. Public Health 2016, 13, 781. [CrossRef] [PubMed]

9. Hansen, M.M.; Jones, R.; Tocchini, K. Shinrin-yoku (Forest bathing) and nature therapy: A state-of-the-art review. Int. J. Environ. Res. Public Health 2017, 14, 851. [CrossRef]

10. Morita, E.; Fukuda, S.; Nagano, J.; Hamajima, N.; Yamamoto, H.; Iwai, Y.; Nakashima, T.; Ohira, H.; Shirakawa, T. Psychological effects of forest environments on healthy adults: Shinrin-yoku (forest-air bathing, walking) as a possible method of stress reduction. Public Health 2007, 121, 54-63. [CrossRef] [PubMed]

11. Park, B.J.; Tsunetsugu, Y.; Kasetani, T.; Hirano, H.; Kagawa, T.; Sato, M.; Miyazaki, Y. Physiological effects of Shinrin-yoku (taking in the atmosphere of the forest) using salivary cortisol and cerebral activity as indicators. J. Physiol. Anthropol. 2007, 26, 123-128. [CrossRef] [PubMed]

12. Tsunetsugu, Y.; Park, B.-J.; Ishii, H.; Hirano, H.; Kagawa, T.; Miyazaki, Y. Physiological effects of shinrin-yoku (taking in the atmosphere of the forest) in an old-growth broadleaf forest in Yamagata Prefecture, Japan. J. Physiol. Anthropol. 2007, 26, 135-142. [CrossRef] [PubMed]

13. Jia, B.B.; Yang, Z.X.; Mao, G.X.; Lyu, Y.D.; Wen, X.L.; Xu, W.H.; Lyu, X.L.; Cao, Y.B.; Wang, G.F. Health effect of forest bathing trip on elderly patients with chronic obstructive pulmonary disease. Biomed. Environ. Sci. 2016, 29, 212-218.

14. Kobayashi, H.; Song, C.; Ikei, H.; Park, B.J.; Lee, J.; Kagawa, T.; Miyazaki, Y. Population-based study on the effect of a forest environment on salivary cortisol concentration. Int. J. Environ. Res. Public Health 2017, 14, 931. [CrossRef] [PubMed]

15. Mao, G.X.; Lan, X.G.; Cao, Y.B.; Chen, Z.M.; He, Z.H.; LV, Y.D.; Wang, Y.Z.; Hu, X.L.; Wang, G.F.; Yan, J. Effects of short-term forest bathing on human health in a broad-leaved evergreen forest in Zhejiang Province, China. Biomed. Environ. Sci. 2012, 25, 317-324. [PubMed]

16. Ochiai, H.; Ikei, H.; Song, C.; Kobayashi, M.; Miura, T.; Kagawa, T.; Li, Q.; Kumeda, S.; Imai, M.; Miyazaki, Y. Physiological and psychological effects of a forest therapy program on middle-aged females. Int. J. Environ. Res. Public Health 2015, 12, 15222-15232. [CrossRef]

17. Komori, T.; Mitsui, M.; Togashi, K.; Matsui, J.; Kato, T.; Uei, D.; Shibayama, A.; Yamato, K.; Okumura, H.; Kinoshita, F. Relaxation effect of a 2-hour walk in Kumano-Kodo Forest. J. Neurol. Neurosci. 2017, 8. [CrossRef]

18. Horiuchi, M.; Endo, J.; Akatsuka, S.; Uno, T.; Hasegawa, T. Influence of forest walking on blood pressure, profile of mood states and stress markers from the viewpoint of aging. J. Aging Gerontol. 2013, 1, 9-17. [CrossRef]

19. Lee, J.; Park, B.J.; Tsunetsugu, Y.; Ohira, T.; Kagawa, T.; Miyazaki, Y. Effect of forest bathing on physiological and psychological responses in young Japanese male subjects. Public Health 2011, 125, 93-100. [CrossRef]

20. Toda, M.; Den, R.; Hasegawa-Ohira, M.; Morimoto, K. Effects of woodland walking on salivary stress markers cortisol and chromogranin A. Complement. Ther. Med. 2013, 21, 29-34. [CrossRef]

21. Antonelli, M.; Barbieri, G.; Donelli, D. Effects of forest bathing (shinrin-yoku) on levels of cortisol as a stress biomarker: A systematic review and meta-analysis. Int. J. Biometeorol. 2019, 63, 1117-1134. [CrossRef]

22. Chrousos, G.P.; Kino, T.; Charmandari, E. Evaluation of the hypothalamic-pituitary-adrenal axis function in childhood and adolescence. Neuroimmunomodulation 2009, 16, 272-283. [CrossRef]

23. Antonelli, M.; Donelli, D. Effects of balneotherapy and spa therapy on levels of cortisol as a stress biomarker: A systematic review. Int. J. Biometeorol. 2018, 62, 913-924. [CrossRef] [PubMed]

24. Grassi, G.; Esler, M. How to assess sympathetic activity in humans. J. Hypertens. 1999, 17, 719-734. [CrossRef]

25. Petrakova, L.; Doering, B.K.; Vits, S.; Engler, H.; Rief, W.; Schedlowski, M.; Grigoleit, J.S. Psychosocial stress increases salivary alpha-Amylase activity independently from plasma noradrenaline levels. PLoS ONE 2015, 10, e0134561. [CrossRef]

26. Nater, U.M.; Rohleder, N. Salivary alpha-amylase as a non-invasive biomarker for the sympathetic nervous system: Current state of research. Psychoneuroendocrinology 2009, 34, 486-496. [CrossRef] [PubMed]

27. DeCaro, J.A. Methodological considerations in the use of salivary $\alpha$-amylase as a stress marker in field research. Am. J. Hum. Biol. 2008, 20, 617-619. [CrossRef]

28. Granger, D.A.; Kivlighan, K.T.; El-Sheikh, M.; Gordis, E.B.; Stroud, L.R. Salivy $\alpha$-amylase in biobehavioral research: Recent developments and applications. Ann. N. Y. Acad. Sci. 2007, 1098, 122-144. [CrossRef]

29. Yamaguchi, M.; Deguchi, M.; Miyazaki, Y. The effects of exercise in forest and urban environments on sympathetic nervous activity of normal young adults. J. Int. Med. Res. 2006, 34, 152-159. [CrossRef] [PubMed] 
30. Carpenter, G.H.; Proctor, G.B.; Anderson, L.C.; Zhang, X.S.; Garrett, J.R. Immunoglobulin A secretion into saliva during dual sympathetic and parasympathetic nerve stimulation of rat submandibular glands. Exp. Physiol. 2000, 85, 281-286. [CrossRef]

31. Allgrove, J.E.; Gomes, E.; Hough, J.; Gleeson, M. Effects of exercise intensity on salivary antimicrobial proteins and markers of stress in active men. J. Sports Sci. 2008, 26, 653-661. [CrossRef]

32. Obayashi, K. Salivary mental stress proteins. Clin. Chim. Acta 2013, 425, 196-201. [CrossRef]

33. Peluso, I.; Raguzzini, A. Salivary and urinary total antioxidant capacity as biomarkers of oxidative stress in humans. Pathol. Res. Int. 2016, 2016, 5480267. [CrossRef]

34. Bach, A.; Penuelas, J.; Clarà, J.; Llusià, J.; Campillo, I.; López, F.; Maneja, R. How should forests be characterized in regard to human health? Evidence from existing literature. Int. J. Environ. Res. Public Health 2020, 17, 1027. [CrossRef] [PubMed]

35. Park, B.J.; Tsunetsugu, Y.; Ishii, H.; Furuhashi, S.; Hirano, H.; Kagawa, T.; Miyazaki, Y. Physiological effects of Shinrin-yoku (taking in the atmosphere of the forest) in a mixed forest in Shinano Town, Japan. Scand. J. For. Res. 2008, 23, 278-283. [CrossRef]

36. Lee, J.; Park, B.J.; Tsunetsugu, Y.; Kagawa, T.; Miyazaki, Y. Restorative effects of viewing real forest landscapes, based on a comparison with urban landscapes. Scand. J. For. Res. 2009, 24, 227-234. [CrossRef]

37. Nater, U.M.; Rohleder, N.; Schlotz, W.; Ehlert, U.; Kirschbaum, C. Determinants of the diurnal course of salivary alpha-amylase. Psychoneuroendocrinology 2007, 32, 392-401. [CrossRef]

38. Borisenkov, M.F.; Erunova, L.A.; Lyuseva, E.M.; Pozdeeva, N.V. Diurnal changes in the total antioxidant activity of human saliva. Hum. Physiol. 2007, 33, 375-376. [CrossRef]

39. Fries, E.; Dettenborn, L.; Kirschbaum, C. The cortisol awakening response (CAR): Facts and future directions. Int. J. Psychophysiol. 2009, 72, 67-73. [CrossRef] [PubMed]

40. Contreras-Aguilar, M.D.; Escribano, D.; Martínez-Subiela, S.; Martínez-Miró, S.; Rubio, M.; Tvarijonaviciute, A.; Tecles, F.; Cerón, J.J. Influence of the way of reporting alpha-amylase values in saliva in different naturalistic situations: A pilot study. PLoS ONE 2017, 12, e0180100. [CrossRef] [PubMed]

41. Tecles, F.; Fuentes-Rubio, M.; Tvarijonaviciute, A.; Martínez-Subiela, S.; Fatjó, J.; Cerón, J.J. Assessment of stress associated with an oral public speech in veterinary students by salivary biomarkers. J. Vet. Med. Educ. 2014, 41, 37-43. [CrossRef] [PubMed]

42. Rohleder, N.; Nater, U.M. Determinants of salivary $\alpha$-amylase in humans and methodological considerations. Psychoneuroendocrinology 2009, 34, 469-485. [CrossRef]

43. Van der Heiden, C.; Bais, R.; Gerhardt, W.; Lorentz, K.; Rosalki, S. IFCC methods for measurement of catalytic concentration of enzymes. Clin. Chim. Acta 1999, 281, S5-S39.

44. Lopez-Jornet, P.; Cayuela, C.A.; Tvarijonaviciute, A.; Parra-Perez, F.; Escribano, D.; Ceron, J. Oral lichen planus: Salival biomarkers cortisol, immunoglobulin A., adiponectin. J. Oral Pathol. Med. 2016, 45, 211-217. [CrossRef] [PubMed]

45. Campos, C.; Guzmán, R.; López-Fernández, E.; Casado, Á. Evaluation of the copper(II) reduction assay using bathocuproinedisulfonic acid disodium salt for the total antioxidant capacity assessment: The CUPRAC-BCS assay. Anal. Biochem. 2009, 392, 37-44. [CrossRef] [PubMed]

46. Rhee, S.G.; Chang, T.S.; Jeong, W.; Kang, D. Methods for detection and measurement of hydrogen peroxide inside and outside of cells. Mol. Cells 2010, 29, 539-549. [CrossRef] [PubMed]

47. Ochiai, H.; Ikei, H.; Song, C.; Kobayashi, M.; Takamatsu, A.; Miura, T.; Kagawa, T.; Li, Q.; Kumeda, S.; Imai, M.; et al. Physiological and psychological effects of forest therapy on middle-aged males with high-normal blood pressure. Int. J. Environ. Res. Public Health 2015, 12, 2532-2542. [CrossRef] [PubMed]

48. Hill, E.E.; Zack, E.; Battaglini, C.; Viru, M.; Viru, A.; Hackney, A.C. Exercise and circulating cortisol levels: The intensity threshold effect. J. Endocrinol. Invest. 2008, 31, 587-591. [CrossRef] [PubMed]

49. Mezzacappa, E.S.; Kelsey, R.M.; Katkin, E.S.; Sloan, R.P. Vagal rebound and recovery from psychological stress. Psychosom. Med. 2001, 63, 650-657. [CrossRef] [PubMed]

50. Koibuchi, E.; Suzuki, Y. Exercise upregulates salivary amylase in humans. Exp. Ther. Med. 2014, 7, 773-777. [CrossRef] [PubMed]

51. Hunter, M.C.R.; Gillespie, B.W.; Chen, S.Y.P. Urban nature experiences reduce stress in the context of daily life based on salivary biomarkers. Front. Psychol. 2019, 10, 722. [CrossRef] [PubMed]

52. Horiuchi, M.; Endo, J.; Takayama, N.; Murase, K.; Nishiyama, N.; Saito, H.; Fujiwara, A. Impact of viewing vs. Not viewing a real forest on physiological and psychological responses in the same setting. Int. J. Environ. Res. Public Health 2014, 11, 10883-10901. [CrossRef] [PubMed]

53. Hayase, M.; Shimada, M. Effects of maternity yoga on the autonomic nervous system during pregnancy. J. Obstet. Gynaecol. Res. 2018, 44, 1887-1895. [CrossRef] [PubMed]

54. Tsujita, S.; Morimoto, K. Secretory IgA in saliva can be a useful stress marker. Environ. Health Prev. Med. 1999, 4, 1-8. [CrossRef]

55. Klentrou, P.; Cieslak, T.; MacNeil, M.; Vintinner, A.; Plyley, M. Effect of moderate exercise on salivary immunoglobulin A and infection risk in humans. Eur. J. Appl. Physiol. 2002, 87, 153-158. [CrossRef] [PubMed]

56. Doimo, I.; Masiero, M.; Gatto, P. Forest and wellbeing: Bridging medical and forest research for effective forest-based initiatives. Forests 2020, 11, 791. [CrossRef] 
57. Bach, A.; Yáñez-Serrano, A.M.; Llusi, J.; Filella, I.; Maneja, R.; Penuelas, J. Human breathable air in a Mediterranean forest: Characterization of monoterpene concentrations under the canopy. Int. J. Environ. Res. Public Health 2020, 17, 4391. [CrossRef] [PubMed]

58. Antonelli, M.; Donelli, D.; Barbieri, G.; Valussi, M.; Maggini, V.; Firenzuoli, F. Forest volatile organic compounds and their effects on human health: A state-of-the-art review. Int. J. Environ. Res. Public Health 2020, 17, 6506. [CrossRef] 